\title{
21st century headache: mapping new territory
}

Peter J. Goadsby ${ }^{1,2^{*}}$ (D), Michel Lantéri-Minet ${ }^{3,4}$, Martin C. Michel ${ }^{5}$, Mario Peres ${ }^{6}$, Mamoru Shibata ${ }^{7}$, Andreas Straube ${ }^{8}$, Tissa Wijeratne ${ }^{9}$, Caty Ebel-Bitoun ${ }^{10}$, Luminita Constantin ${ }^{10}$ and Simon Hitier ${ }^{10}$

\begin{abstract}
Background: With headache experienced by up to $75 \%$ of adults worldwide in the last year, primary headache disorders constitute a major public health problem, yet they remain under-diagnosed and under-treated. Headache prevalence and burden is changing as society evolves, with headache now occurring earlier in life. Contributing factors, mostly associated with changing life style, such as stress, bad posture, physical inactivity, sleep disturbance, poor diet and excess use of digital technology may be associated with the phenomenon that could be labelled as '21st century headache'. This is especially notable in workplace and learning environments where headache impacts mental clarity and therefore cognitive performance. The headache-related impact on productivity and absenteeism negatively influences an individual's behaviour and quality of life, and is also associated with a high economic cost. Since the majority of sufferers opt to self-treat rather than seek medical advice, substantial knowledge on headache prevalence, causation and burden is unknown globally. Mapping the entire population of headache sufferers can close this knowledge gap, leading to better headache management. The broad use of digital technology to gather real world data on headache triggers, burden and management strategies, in self-treated population will allow these sufferers to access appropriate support and medication, and therefore improve quality of life.

Conclusion: These data can yield important insights into a substantial global healthcare issue and form the basis for improved patient awareness, professional education, clinical study design and drug development.
\end{abstract}

Keywords: 21st century headache, Triggers, Cognitive functioning, Over-the-counter medication, Real world evidence, Infodemiology

\section{Background}

Headache disorders are among the main causes of disability worldwide; however, the majority of sufferers are never professionally diagnosed and instead, turn to overthe-counter (OTC) medications to self-manage symptoms [1]. While many other diseases decrease with socioeconomic development, worldwide analysis suggests that migraine and tension-type headache $(\mathrm{TTH})$ are on the rise $[1,2]$. Though predominantly experienced by

\footnotetext{
* Correspondence: peter.goadsby@kcl.ac.uk

${ }^{1}$ NIHR-Wellcome Trust King's Clinical Research Facility, King's College Hospital, London SE5 9PJ, UK

${ }^{2}$ Department of Neurology, University of California, Los Angeles, USA

Full list of author information is available at the end of the article
}

those aged 15-49years, headache incidence in school aged children is increasing, indicating that headache disorders are being reported earlier in life than they were before $[1,3]$. There is accumulating evidence in recent literature that modern lifestyle in industrial countries may have an effect on headache incidence, prevalence and impact. In this short communication, we briefly analyse the phenomenon of '21st century headache'.

\section{Headache triggers associated with 21 st century lifestyle}

While general lifestyle factors, such as poor diet, stress and posture, are known causal factors, other aspects of modern life also influence headache disorders [1]. The

\section{$\triangle B M C$}

(c) The Author(s). 2021 Open Access This article is licensed under a Creative Commons Attribution 4.0 International License, which permits use, sharing, adaptation, distribution and reproduction in any medium or format, as long as you give appropriate credit to the original author(s) and the source, provide a link to the Creative Commons licence, and indicate if changes were made. The images or other third party material in this article are included in the article's Creative Commons licence, unless indicated otherwise in a credit line to the material. If material is not included in the article's Creative Commons licence and your intended use is not permitted by statutory regulation or exceeds the permitted use, you will need to obtain permission directly from the copyright holder. To view a copy of this licence, visit http://creativecommons.org/licenses/by/4.0/ The Creative Commons Public Domain Dedication waiver (http://creativecommons.org/publicdomain/zero/1.0/) applies to the data made available in this article, unless otherwise stated in a credit line to the data. 
recently increased use of digital technology is associated with increased risk of obesity, fatigue and headache; thus, headache incidence has been linked to prolonged $(>8 \mathrm{~h} /$ day) computer use in IT professionals in China and to excessive ( $>4 \mathrm{~h} /$ day) video game use in adolescents in Brazil $[4,5]$. Additionally, increased smartphone usage has been linked to headache, sleep disturbance, cognitive impairment and fatigue, with call frequency significantly correlated with headache risk [6].

More recently, the coronavirus disease 2019 (COVID19) pandemic has been associated with both increased and decreased headache frequency [7]. In addition to being reported as a symptom of infection, headache frequency and severity increased in uninfected individuals due to psychological stress, social isolation, sleep disruption and poor dietary habits $[8,9]$. New laws and policies introduced to mitigate the spread of COVID-19 have inevitably increased our dependence on digital technology, with working from home, online education and socialisation leading to increased average screen time [10]. The pandemic may therefore have unexpected consequences in terms of headache frequency, and future studies will determine the full extent of these consequences.

\section{Headache impact on cognitive and daily functionality}

Both migraine and TTH negatively impact aspects of 'mental clarity', such as concentration, attention, reading, processing speed and memory $[11,12]$. The cognitive impact of migraine has been well characterised, with multiple studies showing that migraine sufferers experience greater memory deficits during an attack compared with other headache types; however, the evidence for the impact of TTH on cognitive functioning is limited [11, 13]. One study has shown that TTH affects psychomotor performance and is associated with reduced quality of life [11].

Headache disorders contribute to distraction and poor concentration that define presenteeism at work; recent studies in Europe showed that only 50\% of headache sufferers with presenteeism completed their normal working day $[14,15]$. Absenteesim is also a problem: approximately $22 \%$ of migraine sufferers and $10 \%$ of TTH sufferers take several days per year off work due to headache [16]. Unsurprisingly, in line with the rising incidence of headache, the headache-associated years of life with disability have been increasing worldwide since 1990 [1]. The cognitive impact and loss of productivity may also be linked to anxiety, avoidance behaviour, reduced social interactions and lifestyle compromise reported by $16 \%$ of migraine sufferers and $20 \%$ of TTH sufferers $[17,18]$.

\section{Changing the paradigm: non-doctor headache}

Although effective treatments exist, studies have shown that approximately $60 \%$ of migraine suffers and $80 \%$ of
TTH sufferers never seek medical advice $[16,19,20]$. There is global variation in access to adequate healthcare, availability of medication, education and specific treatment guidelines, with headaches generally considered to have low priority in public health systems [1]. Alongside headache severity and frequency, the rate of healthcare utilisation is influenced by demographic and socioeconomic factors, such as age, occupation and status [21]. Often, sufferers attribute headache to muscular tension or everyday life situations, such as stress, relationships and hormonal fluctuations, and therefore believe that medical care is unnecessary [20]. This population of headache sufferers, that could be referred to as the 'non-doctor treated headache' (NDH) population, relies on OTC medication for symptom relief [22]. Consequently, there are limited data on the management of headache in the NDH population with respect to headache type, reduction in quality of life, triggers, OTC medication and non-pharmacological management techniques [23].

While randomised controlled trials (RCTs) adequately assess professionally diagnosed and managed headache, the NDH population should be captured by real world evidence studies, a number of which have been successfully undertaken and delivered important insights in headache-related behaviour and experiences [24]. These studies highlighted the need to understand better the $\mathrm{NDH}$ population and to develop strategies to engage and educate headache sufferers. Here, the digital technology can serve as a double-edged sword: while possibly attributing to rising incidence and prevalence of headache, it provides an enormous pool of real world data. An increasing number of smartphone applications capture and record headache frequency, intensity, triggers, duration and medication choice [25]. The accumulation of such data via freely available smartphone apps could predict headache days and allow tracking of headacherelated impact on activities, productivity and quality of life [25]. Such technology could also be used to deliver non-pharmacological therapies, such as relaxation techniques and cognitive behavioural therapy [26]. Researchers studying cardiovascular diseases and diabetes have embraced the possibility to collect real world data directly from patients without time-consuming clinical visits and are becoming increasingly aware of the possibilities that smartphone applications may offer for selfmanagement of chronic conditions [27, 28]. Of particular importance in this regard would be collection of information on relevant comorbidities, particularly pain syndromes, which may contribute to overall disability $[29,30]$. Contemporary technology allows the integration of data in real time using state of the art analysis techniques (such as artificial intelligence) in a novel approach termed infodemiology. The time is ripe to use 


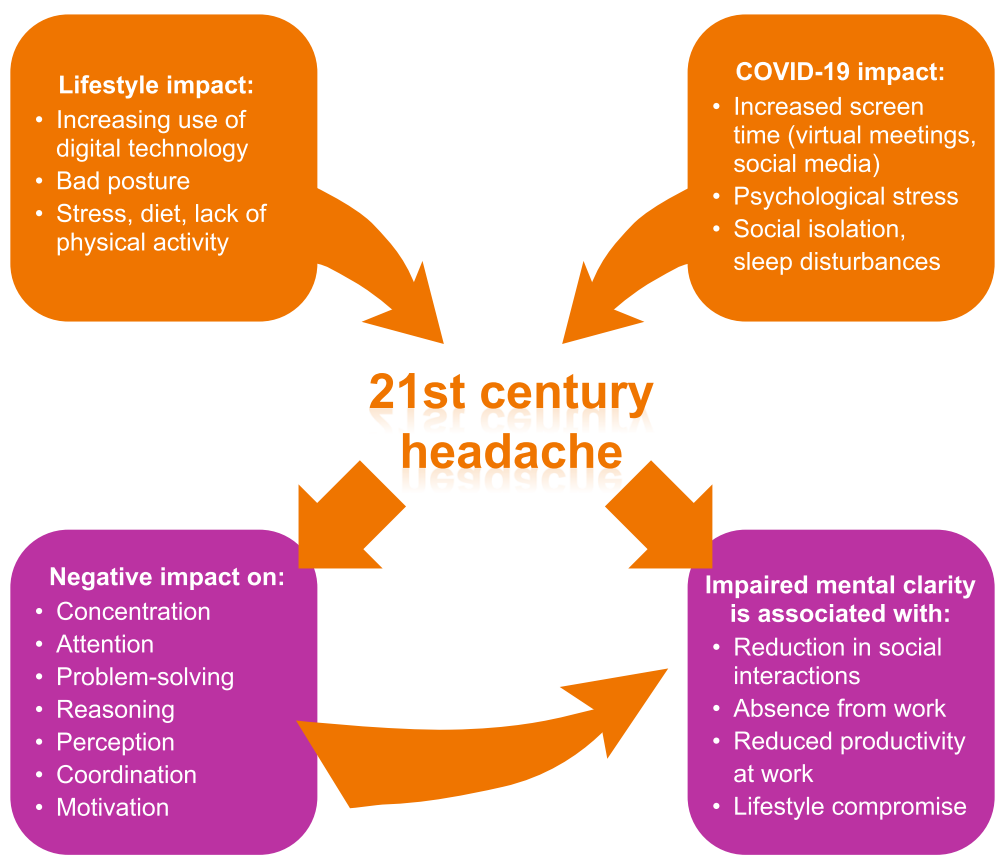

Fig. 1 Triggers, suspected impact and burden of 21st century headache

21st century technology to map the new territory of 21 st century headache.

\section{Conclusions}

Headache prevalence is reportedly increasing among all age groups, and the cognitive burden on individuals' mental clarity comes at a cost to society as a whole (Fig. 1). Because causal factors seem to evolve with socioeconomic development, it is important to identify the true burden and triggers related to '21st century headache' in real world settings [1,3]. By exploiting widely available digital technology, such as smartphone apps, population-based real world data can be collected in real time to enhance our knowledge of triggers, impact and self-medication practices. Clinical experts and modern analysis techniques, such as artificial intelligence and machine learning, should be engaged in the analysis of these data to help identify NDH-relevant and specific outcome measures that should be further validated in RCTs assessing the impact of 21st century headache on cognitive abilities, functionality and society. Ultimately, these studies should inform medical training and treatment guidelines for the NDH population. Providing new guidelines to trained pharmacists and establishing an educational programme for the general population will empower headache sufferers to manage better their condition and decrease the burden of 21st century headache.

\section{Abbreviations}

OTC: Over-the-counter; NDH: Non-doctor-treated headache; RCT: Randomised controlled trial; $T \mathrm{HH}$ : Tension-type headache

\section{Acknowledgments}

This study was sponsored by Sanofi. Editorial support was provided by Olga Ucar and Nichola Cruickshanks of inScience Communications, Springer Healthcare Ltd., UK, and was funded by Sanofi.

\section{Authors' contributions}

The manuscript concept emerged from discussions between all authors; PJG led the development of the primary draft. All authors commented on the primary draft for critical intellectual content and read and approved the submitted version.

\section{Funding \\ Sanofi.}

Availability of data and materials

Not applicable.

\section{Declarations}

Ethics approval and consent to participate Not applicable.

\section{Consent for publication}

Not applicable.

\section{Competing interests}

PJG reports grants and personal fees from Amgen and Eli-Lilly and Company, grant from Celgene, and personal fees from Alder Biopharmaceuticals, Aeon Biopharma, Allergan, Biohaven Pharmaceuticals Inc., Clexio, Electrocore LLC, eNeura, Epalex, GlaxoSmithKline, Impel Neuropharma, MundiPharma, Novartis, Pfizer, Praxis, Sanofi, Santara Therapeutics, Satsuma, Teva Pharmaceuticals, Trigemina Inc., WL Gore, and personal fees from MedicoLegal work, Massachusetts Medical Society, Up-to-Date, Oxford University Press, and Wolters 
Kluwer; and a patent magnetic stimulation for headache assigned to eNeura without fee.

MLM reports personal fees from Allergan, Amgen, ATI, BMS, Astellas, Boehringer Ingelheim, Boston Scientific, CoLucid, Convergence,

GlaxoSmithKline, Grunenthal, grants from Eli Lilly, Medtronic, Novartis, Pfizer, Reckitt Benckiser, Saint-Jude, Sanofi-Aventis, Teva Pharmaceuticals, Zambon. MCM reports consulting fees from Sanofi-Aventis.

MP reports consulting fees Teva, Libbs, Eli Lilly, Novartis, Allergan, Sanofi, Pfizer.

MS reports consulting fees from Amgen, Eli Lilly, Otsuka, Sanofi-Aventis. Speaking fees from Amgen, Daiichi-Sankyo, Takeda, Eisai. Reimbursement for travel from American Headache Society.

AS reports honoraria for consulting and educational lectures from Allergan Pharma, Bayer, Desitin Arzneimittel, electroCore, Lilly Germany, Novartis Pharma, Sanofi Aventis, and TEVA.

TW is a member of the Headache Expert Steering Committee sponsored by Sanofi.

LC, CEB and SH are all employees of Sanofi.

\section{Author details}

'NIHR-Wellcome Trust King's Clinical Research Facility, King's College Hospital, London SE5 9PJ, UK. ${ }^{2}$ Department of Neurology, University of California, Los Angeles, USA. ${ }^{3}$ Pain Department and FHU InovPain, CHU Nice - Côte Azur Université, Nice, France. ${ }^{4}$ INSERM U1107 Migraine and Trigeminal Pain, Auvergne University, Clermont-Ferrand, France. ${ }^{5}$ Department of Pharmacology, Johannes Gutenberg University, Mainz, Germany. ${ }^{6}$ Universidade Federal de São Paulo, São Paulo, Brazil. 'Department of Neurology, Tokyo Dental College Ichikawa General Hospital, Chiba, Japan. ${ }^{8}$ Department of Neurology, Ludwig-Maximilians University, Munich, Germany. ${ }^{9}$ AIMSS, Department of Neurology, Melbourne Medical School, Sunshine Hospital, Western Health, The University of Melbourne, Melbourne, Australia.

${ }^{10}$ Sanofi, 82, Avenue Raspail, 94255 Gentilly Cedex, France.

Received: 23 December 2020 Accepted: 16 March 2021

Published online: 01 April 2021

\section{References}

1. GBD 2016 Headache Collaborators (2018) Global, regional, and national burden of migraine and tension-type headache, 1990-2016: a systematic analysis for the Global Burden of Disease Study 2016. Lancet Neurol 17(11): 954-976

2. World Health Organization (2011) Atlas of headache disorders and resources in the world 2011. Avaliable from: https://www.who.int/mental_health/ma nagement/atlas_headache_disorders/en/. Accessed 24 Nov 2020

3. Straube A et al (2013) Headache in school children: prevalence and risk factors. Dtsch Arztebl Int 110(48):811-818

4. Xavier MK et al (2015) Prevalence of headache in adolescents and association with use of computer and videogames. Cien Saude Colet 20(11): 3477-3486

5. Li C et al (2020) Prevalence of primary headache disorders among information technology staff in China: the negative effects of computer use and other correlative factors. BMC Public Health 20(1):443

6. Wang $J$ et al (2017) Mobile phone use and the risk of headache: a systematic review and meta-analysis of cross-sectional studies. Sci Rep 7(1): 12595

7. Altamura C et al (2020) Locking down the CGRP pathway during the COVID-19 pandemic lockdown: the PandeMig study. Neurol Sci 41(12): 3385-3389

8. Porta-Etessam J et al (2020) Spectrum of headaches associated with SARSCoV-2 infection: study of healthcare professionals. Headache. 60:1697-1704

9. Al-Hashel JY et al (2020) Impact of coronavirus disease 2019 (COVID-19) pandemic on patients with migraine: a web-based survey study. J Headache Pain. 21(1):115

10. Nagata JM et al (2020) Screen time for children and adolescents during the coronavirus disease 2019 pandemic. Obesity (Silver Spring) 28(9):1582-1583

11. Smith AP (2016) Acute tension-type headaches are associated with impaired cognitive function and more negative mood. Front Neurol 7:42

12. Gil-Gouveia R et al (2015) Cognitive dysfunction during migraine attacks: a study on migraine without aura. Cephalalgia. 35(8):662-674

13. Moore DJ et al (2013) Headache impairs attentional performance. Pain. 154(9):1840-1845
14. Monzani $L$ et al (2018) Anxiety and the severity of tension-type headache mediate the relation between headache presenteeism and workers productivity. PLoS One 13(7):e0201189

15. Andrée C et al (2014) Headache yesterday in Europe. J Headache Pain. 15(1):33

16. Suzuki $\mathrm{N}$ et al (2014) Prevalence and characteristics of headaches in a socially active population working in the Tokyo metropolitan area -surveillance by an industrial health consortium. Intern Med 53(7):683-689

17. Steiner TJ et al (2014) The impact of headache in Europe: principal results of the Eurolight project. J Headache Pain. 15(1):31

18. Lampl C et al (2016) Headache, depression and anxiety: associations in the Eurolight project. J Headache Pain. 17:59

19. Steiner TJ et al (2019) Headache service quality: the role of specialized headache centres within structured headache services, and suggested standards and criteria as centres of excellence. J Headache Pain. 20(1):24

20. Headache Classification Committee of the International Headache Society (IHS) (2018) The international classification of headache disorders, 3rd edition. Cephalalgia. 38(1):1-211

21. Müller B et al (2020) Use of outpatient medical care by headache patients in Germany: a population-based cross-sectional study. J Headache Pain. 21(1):49

22. Haag $\mathrm{G}$ et al (2011) Self-medication of migraine and tension-type headache: summary of the evidence-based recommendations of the deutsche Migräne und Kopfschmerzgesellschaft (DMKG), the deutsche Gesellschaft für Neurologie (DGN), the Österreichische Kopfschmerzgesellschaft (ÖKSG) and the Schweizerische Kopfwehgesellschaft (SKG). J Headache Pain 12(2):201217

23. Fernando Prieto Peres M et al (2019) Non-pharmacological treatment for primary headaches prevention and lifestyle changes in a low-income Community of Brazil: a randomized clinical trial. Headache. 59:86-96

24. Eysenbach G (2009) Infodemiology and infoveillance: framework for an emerging set of public health informatics methods to analyze search, communication and publication behavior on the internet. J Med Internet Res 1:e11

25. Vo P et al (2018) Burden of migraine in Europe using self-reported digital diary data from the migraine buddy $\odot$ application. Neurol Ther 7(2):321-332

26. Minen MT et al (2019) Smartphone-based migraine behavioral therapy: a single-arm study with assessment of mental health predictors. NPJ Digit Med 2:46

27. Li KHC et al (2019) The current state of Mobile phone apps for monitoring heart rate, heart rate variability, and atrial fibrillation: narrative review. JMIR Mhealth Uhealth 7(2):e11606

28. Jimenez $\mathrm{G}$ et al (2019) Examining diabetes management apps recommended from a Google search: content analysis. JMIR Mhealth Uhealth. 7(1):e11848

29. Giamberardino MA et al (2015) Impact of migraine on fibromyalgia symptoms. J Headache Pain. 17:28

30. Affaitati $\mathrm{G}$ et al (2018) Effects of topical vs injection treatment of cervical myofascial trigger points on headache symptoms in migraine patients: a retrospective analysis. J Headache Pain. 19(1):104

\section{Publisher's Note}

Springer Nature remains neutral with regard to jurisdictional claims in published maps and institutional affiliations.

\section{Ready to submit your research? Choose BMC and benefit from:}

- fast, convenient online submission

- thorough peer review by experienced researchers in your field

- rapid publication on acceptance

- support for research data, including large and complex data types

- gold Open Access which fosters wider collaboration and increased citations

- maximum visibility for your research: over $100 \mathrm{M}$ website views per year

At $\mathrm{BMC}$, research is always in progress.

Learn more biomedcentral.com/submissions 